lymphoma, or Brill-Symmers syndrome. They emphasized that only consideration of several features could enable the distinction to be made, and they noted as well that the reactive hyperplasia tended to be localized, whereas the lymphoma tended to be generalized. Therapeutically the enlarged masses of lymph nodes produced by follicular lymphoma respond well to radiotherapy or to chemotherapy, and such treatment will also reduce nodes later found to be non-neoplastic. To-day, when thoracotomy can be undertaken in centres with proper modern facilities, the risk of operative removal of such a mediastinal mass as occurred in the case reported here may well be worth while; but if physicians elsewhere meet such a case treatment with radiotherapy or even chemotherapy might be adequate.

\section{Thymectomy and Myasthenia Gravis}

The first well-documented association of a thymic tumour with myasthenia gravis was reported in 1901 by L. Loquer and C. Weigert, ${ }^{1}$ but H. R. Viets and R. S. Schwab ${ }^{2}$ state that two years before this Oppenheim had mentioned the association in a paper in which he showed that there were no pathological changes in the nervous system in myasthenia gravis. The first thymectomy for myasthenia was performed by Sauerbruch in $1911^{3}$ on a patient who also suffered from thyrotoxicosis. Some improvement in the myasthenia was noted. In $1937^{45}$ the same surgeon operated on two myasthenic patients who had thymic tumours, but both patients died of mediastinitis.

But it was A. Blalock ${ }^{6}$ in 1936 who first showed the value of thymectomy in the treatment of myasthenia. As well as operating on patients with thymic tumours he also removed the organ from patients without a tumour. In 1942 Sir Geoffrey Keynes $^{7}$ performed the first thymectomy for myasthenia in Great Britain, and it is as a result of his work on the subject that the value of the operation in selected cases of myasthenia has been established. From an early stage he emphasized the importance of considering separately patients with and without a tumour when assessing the results of operation. Tumours of the thymus are present in about $15 \%$ of myasthenic patients, ${ }^{8}$ and with careful radiological techniques ${ }^{9}$ if a tumour is present it can usually be seen.

In $1958 \mathrm{~J}$. A. Simpson ${ }^{10}{ }^{11}$ surveyed Keynes's results in 294 operated patients and compared them with those obtained in 110 patients who had not been operated on. He found that fewer women died of myasthenia if their thymus had been removed than would be expected if they were treated with drugs alone. Moreover, thymectomy also increases the number of women very greatly improved ten years or more after the onset of the illness. In the smaller number of male patients similar trends were found, but the beneficial results of

\footnotetext{
1 Loquer, L., and Weigert, C., Neurol. Zbl., 1901, 20, 594.

Viets, H. R., and Schwab, R. S., Thymectomy for Myasthenia Gravis, 1960. Charles C. Thomas, Springfield, IIl.

S Schumacher and Roth, Mitt. Grenzgeb. Med. Chir., 1913, 25, 746.

- Adler, H., Arch. Klin. Chir., 1937, 189, 529.

$s$ Obedtsch, R. A., Arch. path. Anat., 1937, 300, 319.

Blalock, A., Mason, M. F., Morgan, H. J., and Riven, S. S., Ann. Surg., 1939, 110, 544

' Keynes, G., Brit. F. Surg., 1946, 33, 201.

Her., 1955, 42, 449.

Harper, R. A., Kemp, and Guyer, P. B., Clin. Radiology, 1965, 16, 97

Simpson, J. A., Brain, 1958, 81, 112

Brit. med. F., 1959, 1, 288.

Henson, R. A., Stern, G. M., and Thompson, V. C., Brain, 1965 ,
}

operation were not so clearly established. In general the best results were obtained with a younger than average age of onset, a shorter pre-operative duration of the disease, and a younger age at the time of operation. Simpson considered that a good result was more probable if myasthenia had been present for less than five years before operation, but there were some strikingly successful results in patients with longer histories. He found that the prognosis is poor if a thymoma is present but that pre-operative radiotherapy might be beneficial.

R. A. Henson, G. M. Stern, and V. C. Thompson ${ }^{12}$ have recently reported their results from the London Hospital; 36 operations were performed, six of which were for thymomas. Their indications for operation in cases without radiological evidence of a tumour were those now fairly generally accepted-first, patients under the age of 30 with a history of less than two years in whom symptoms were not adequately controlled by drug treatment; and, secondly, a smaller group, irrespective of age of onset, with symptoms of five years' or less duration who were severely handicapped in spite of energetic medical treatment. Their results were most encouraging, "being entirely satisfactory in $70 \%$." By this they mean that there had been complete remission of symptoms or that only minor symptoms controlled by a small dose of cholinergic drugs persisted. They stress, as have previous authors, the very gradual improvement which often takes place, and emphasize, as Keynes has done in the past, that thymectomy should not be carried out as an emergency in a myasthenic crisis. Two patients died after operation, but these deaths were early in the series before modern methods of dealing with respiratory failure were available. Two patients died later, one suddenly nine months after operation, and the other, who also had thyrotoxicosis, of respiratory failure six months after operation, having shown no postoperative improvement in the myasthenia.

The value of thymectomy in selected cases of myasthenia gravis is thus well established. When a thymoma cannot be shown radiologically, operation gives the best chance of relief of symptoms, or at any rate produces considerable improvement in patients under the age of about 45 in whom the disability is getting worse despite adequate medical treatment. The problem of patients in whom a thymoma is present is more difficult, and a study of a large series of cases is not yet available. Simpson's study of Sir Geoffrey Keynes's series suggests that deep $x$-ray therapy before removal of the tumour and thymus may give the best results.

\section{A Problem in Bacterial Endocarditis}

Sensitivity to penicillin in a patient with bacterial endocarditis presents a difficult problem. The antibiotic or combination of them used in treating this disease must be fully bactericidal, or eventual relapse is almost certain. Bactericidal antibiotics other than penicillin are less effective against streptococci and more toxic. Vancomycin might be the best choice, but it is also difficult to administer. If penicillin must be given at all costs, there are three ways in which this can be made possible. One is desensitization, but this is uncertain, time-consuming, and hazardous. Another is to protect the patient with an

\footnotetext{
Maslansky, L., and Sanger, M. D., Antibiot. and Chemother., 1952, 2 , 385.

${ }^{2}$ Balme, H. W., and Dormer, A. E.. Brit. med. F., 1954, 1, 500

3 Raper, A. J., and Kemp, V. E., New Engl. ¥. Med., 1965, 273, 297.
} 
antihistamine. This was first suggested by L. Maslansky and M. D. Sanger, ${ }^{1}$ who claimed almost to have eliminated reactions in sensitized patients by adding $10 \mathrm{mg}$. chlortrimeton maleate to the penicillin itself. H. W. Balme and A. E. Dormer ${ }^{2}$ successfully treated a second attack of bacterial endocarditis in a 14-year-old girl who had reacted violently to her first dose of penicillin by first mixing $50 \mathrm{mg}$. mepyramine maleate with each dose, and after three days replacing this with oral promethazine hydrochloride, $25 \mathrm{mg}$. 6-hourly.

The third alternative is described by A. J. Raper and V. E. Kemp, ${ }^{3}$ who review six published cases so treated and describe three of their own. This is the administration of corticosteroids, starting them shortly before the course of penicillin is begun. Prednisone was given to each of their patients, in a dose not usually exceeding $60 \mathrm{mg}$. daily, and often less. An attempt was made to keep it as low as possible, and when on several occasions a skin eruption developed the dose had to be increased. Nothing more serious occurred, and full courses of penicillin in two patients and ampicillin in the third, all combined with streptomycin, were successfully completed and the infection was eradicated. One patient had a recurrence seven months later and died; the others have remained well.

This accessory treatment is not itself without risk, as the authors admit, and they emphasize the necessity of fully adequate antibiotic treatment. That it is so they verify by determining the dilution in which the serum is not only bacteriostatic but bactericidal for the infecting organism, and they aim at a level of at least 1 in 8 . In order to reach this one patient had to be given 24 million units of penicillin daily. It is perhaps a matter of opinion whether steroids or antihistamines are better for this purpose, but unquestionably any patient with bacterial endocarditis likely to respond to penicillin, alone or in combination-and there are very few indeed who will not-should be given the benefit of it under one or other form of protection.

\section{Peyer's Patches Again}

The collections of lymphoid tissue in the small intestine known as Peyer's patches were of much interest in the past, when typhoid fever was prevalent, because they were common sites of intestinal ulceration, haemorrhage, and perforation. But who was Peyer? To answer this question we turn to that indispensable reference book Notable Names in Medicine by Hamilton Bailey and W. J. Bishop ${ }^{1}$ and find that the patches are named after Johann Peyer (1653-1712), Professor of Medicine at Schaffhausen in Switzerland. But we learn also that these little intestinal landmarks had previously been described by the Danish anatomist Niels Stensen (1638-86), the discoverer of Stensen's duct. But what are Peyer's patches when viewed with the microscope ? Nothing but dense aggregations of lymphoid follicles. They vary in size in accordance with the number of follicles which compose them. Adjacent to them the lamina propria and neighbouring submucosa is generally infiltrated with lymphocytes.

\footnotetext{
' Bailey, H., and Bishop, W. J., Notable Names in Medicine and Surgery 3rd ed., 1959. H. K. Lewis, London.

2 Cornes, J. S., Gut, 1965, 6, 225.
}

If interest in Peyer's patches declined with the incidence of typhoid fever it has been revived by recent speculations on the function of lymphocytes. Anything new about lymphoid tissue is of renewed interest. For this reason two recent articles by J. Cornes ${ }^{2}$ should be noted. One is on the development of Peyer's patches and the other is cn the effect of age on their structure and number. This author reports that Peyer's patches are well formed in foetal life, and that they generally increase in numbers until childhood. Then they rapidly become fewer after puberty and continue to decline steadily thereafter, though a few may persist even to extreme old age. In this respect they resemble the lymphoid follicles of the large intestine, the number of which also declines with advancing years.

\section{Commonwealth Fund}

Now that a Royal Commission is inquiring into medical education in Britain some research being financed by the Commonwealth Fund, of New York, is specially apposite. Though its title has nothing to do with the British Commonwealth, many citizens of Britain, Australia, New Zealand, and of some other countries have had occasion to be grateful to its founder. She was Mrs. Stephen V. Harness, who on 18 October 1918 created a fund "to do something for the welfare of mankind."

The latest annual report of the Fund shows it has been taking a special interest in financing research into various aspects of medical education. No fewer than ten Fellows for the year 1964-5 were nominated by the Association for the Study of Medical Education (A.S.M.E.), of Great Britain. Most of the awards were for two to three months' travel among North American medical schools. The subjects they are to study include: methods of admission of students to medical schools; organization of elective work by the students ; programmes of continuing education for the general practitioner; value of internships ; undergraduate curricula and graduate training; teaching of microbiology ; examination by multiple choice tests; and methods of teaching ophthalmology. These projects form only a part of the research into medical education being financed by the Fund this year, and when the whole is co-ordinated it should provide a stimulating survey of current ideas and methods.

The medical profession has for many years been notable for possessing something more than a speculative interest in the best ways of educating its members-namely, a capacity to carry out research into the subject. But in some respects Britain can learn from the U.S.A., and the inquiries that the Fellows are now enabled to make there will be studied attentively here. These latest grants will certainly help the Commonwealth Fund to fulfil its main aims: to concentrate the bulk of its resources on problems affecting the health of the public, and to maintain and strengthen its efforts to foster international understanding.

Another helpful contribution from A.S.M.E. was a conference held last week in Birmingham to discuss a particular method of providing the practising doctor with help in keeping up to date. This is the postgraduate medical centre. The structure, connexions, and finances of these centres were explored by speakers experienced in the training of postgraduate as well as undergraduate students, and a report of their proceedings appears at page 1237 . 